\title{
Desempenho de novilhos de corte em pastos de capim-tanzânia sob quatro alturas de desfolha
}

\author{
[Performance of steers on pasture of Tanzania grass under four defoliation heights]
}

\author{
R.P. Barbero ${ }^{1}$, M.A.A.F. Barbosa ${ }^{2}$, L.M. Castro $^{2}$, E.L.A. Ribeiro ${ }^{2}$, I.Y. Mizubuti ${ }^{2}$,
} V.H. Bumbieris Júnior ${ }^{2}$, L.D.F. Silva ${ }^{2}$, F.L. Massaro Júnior ${ }^{2}$

${ }^{1}$ Faculdade de Ciências Agrárias e Veterinárias - UNESP - Jaboticabal, SP

${ }^{2}$ Universidade Estadual de Londrina - UEL - Londrina, PR

\begin{abstract}
RESUMO
Determinou-se a melhor altura de pastejo do capim-tanzânia (Panicum maximum Jacq. cv. Tanzânia) sob lotação contínua e com taxa de lotação variável na produção de bovinos de corte. A área experimental, de 12 hectares, foi dividida em piquetes de um hectare cada, com três repetições para cada altura $-20 ; 40 ; 60$ e $80 \mathrm{~cm}$. Foram utilizados, em cada piquete, três bovinos machos, da raça Nelore, mais animais adicionais conforme necessidade de ajuste à altura pretendida. $\mathrm{O}$ delineamento experimental foi inteiramente ao acaso. A taxa de lotação apresentou comportamento linear negativo em razão das alturas de pastejo em todas as estações do ano, e o mesmo efeito foi observado com o ganho de peso vivo por hectare, enquanto o ganho médio diário apresentou comportamento contrário. Alturas de capim-tanzânia entre 40 e $60 \mathrm{~cm}$, sob lotação contínua, possibilitam bom ganho de peso médio diário em bovinos de corte e boa produção por hectare.
\end{abstract}

Palavras-chave: bovino de corte, ganho de peso, ganho por hectare, lotação contínua

\begin{abstract}
This study was carried out to evaluate the effects of four grazing heights under continuous stocking of Tanzânia grass (Panicum maximum Jacq. Cv. Tanzânia) on the stocking rate, performance and beef production per hectare. The experimental area was 12 hectares, divided into paddocks with one hectare each, with three replicates each (20,40, 60 and $80 \mathrm{~cm})$. There were three male Nellore bovines per paddock, adding animals as needed to adjust the desired heights in a completely randomized design. The stocking rate had a negative linear function of grazing heights in all seasons regarding yield per hectare, while the average daily gain showed opposite behavior. Apparently, Tanzânia grass heights between 40 and $60 \mathrm{~cm}$ under continuous stocking enable good average daily weight gain in beef cattle, and high yield per hectare.
\end{abstract}

Keywords: average daily gain, continuous stocking, gain per hectare

\section{INTRODUÇÃO}

A produção de bovinos de corte no Brasil faz dos pastos a principal fonte de alimento dos rebanhos (Castro et al., 2010), o que caracteriza a pecuária de corte nacional não só como de custos de produção relativamente baixos (Baroni et al., 2010), mas também como extremamente susceptível a variações de produtividade das plantas forrageiras. O sistema de pastejo que faz uso da lotação contínua deve possuir mecanismos eficazes de ajuste da taxa de lotação, pois a capacidade de suporte das pastagens apresenta variações significativas em função das estações (Ribeiro et al., 2011) e sabese que o aumento da taxa de lotação tende a reduzir o desempenho do animal (Almeida et al., 2002).

Características como o bom valor nutricional, excelentes características agronômicas e o elevado consumo pelos animais são fatores positivos à disseminação do capim-tanzânia, que tem se mostrado muito adaptado ao Brasil e proporcionado elevado desempenho dos rebanhos (Cecato et al., 2001).

Recebido em 20 de março de 2012

Aceito em 12 de setembro de 2013

E-mail: rondinelibarbero@zootecnista.com.br

Apoio financeiro: $\mathrm{CNPq}$ 
Barbosa et al. (2006) ressaltam a necessidade do entendimento das respostas e adaptações morfofisiológicas da forrageira a variações quanto às intensidades de desfolha e altura de pastejo às quais é submetida. Nesse contexto, Hodgson (1990) alerta que a intensidade de pastejo pode influenciar na quantidade de forragem produzida e, por consequência, no desempenho produtivo dos rebanhos, sendo a taxa de lotação, fundamentada em parâmetros como a altura do dossel forrageiro, um fator determinante no desenvolvimento da planta e, consequentemente, na eficiência de colheita da forragem pelos animais.

Da Silva e Nascimento Júnior (2007) discutem a praticidade e a viabilidade da aplicação em campo de estratégias de manejo do pastejo, com metas de altura do dossel forrageiro como alternativa viável a potencializar a produtividade pecuária. Para o estabelecimento das metas de pastejo, é fundamental o entendimento dos efeitos gerados pela intensidade de desfolha sobre os parâmetros produtivos na pecuária de corte, em cada estação de produção. O objetivo deste trabalho foi determinar a melhor altura de pastejo do capim-tanzânia sob lotação contínua e com taxa de lotação variável, na produção de bovinos de corte.

\section{MATERIAL E MÉTODOS}

O trabalho foi realizado no município de Cidade Gaúcha, PR, a 550m de altitude. Segundo a classificação de Köppen, o clima da região é $\mathrm{Cfa}$. $\mathrm{O}$ período experimental foi de dezembro de 2009 a dezembro de 2010. As informações referentes à pluviosidade e às temperaturas no período experimental encontram-se na Fig. 1. O solo da área experimental é podzólico vermelho-amarelo, considerado de baixa fertilidade natural, típico do arenito Caiuá (Barbosa et al., 2006). Análise química do solo à camada arável apresentou os seguintes resultados: $\mathrm{pH}$ em água $=6,03$; $\mathrm{Ca}^{+2}=1,74 \mathrm{cmol} / \mathrm{dm}^{3} ; \mathrm{Mg}^{+2}=0,52 \mathrm{mmol}_{\mathrm{c}} / \mathrm{dm}^{3} ;$ $\mathrm{K}^{+}=0,23 \mathrm{mmol} / \mathrm{dm}^{3} ; \mathrm{Na}^{+}=0,00 \mathrm{cmol} / \mathrm{dm}^{3}$; $\mathrm{P}$ disponível $=2,36 \mathrm{mg} / \mathrm{dm}^{3}$; CTC efetiva $=$ $2,49 \mathrm{cmol} / \mathrm{dm}^{3}$; e $\mathrm{Al}=0,00 \%$.

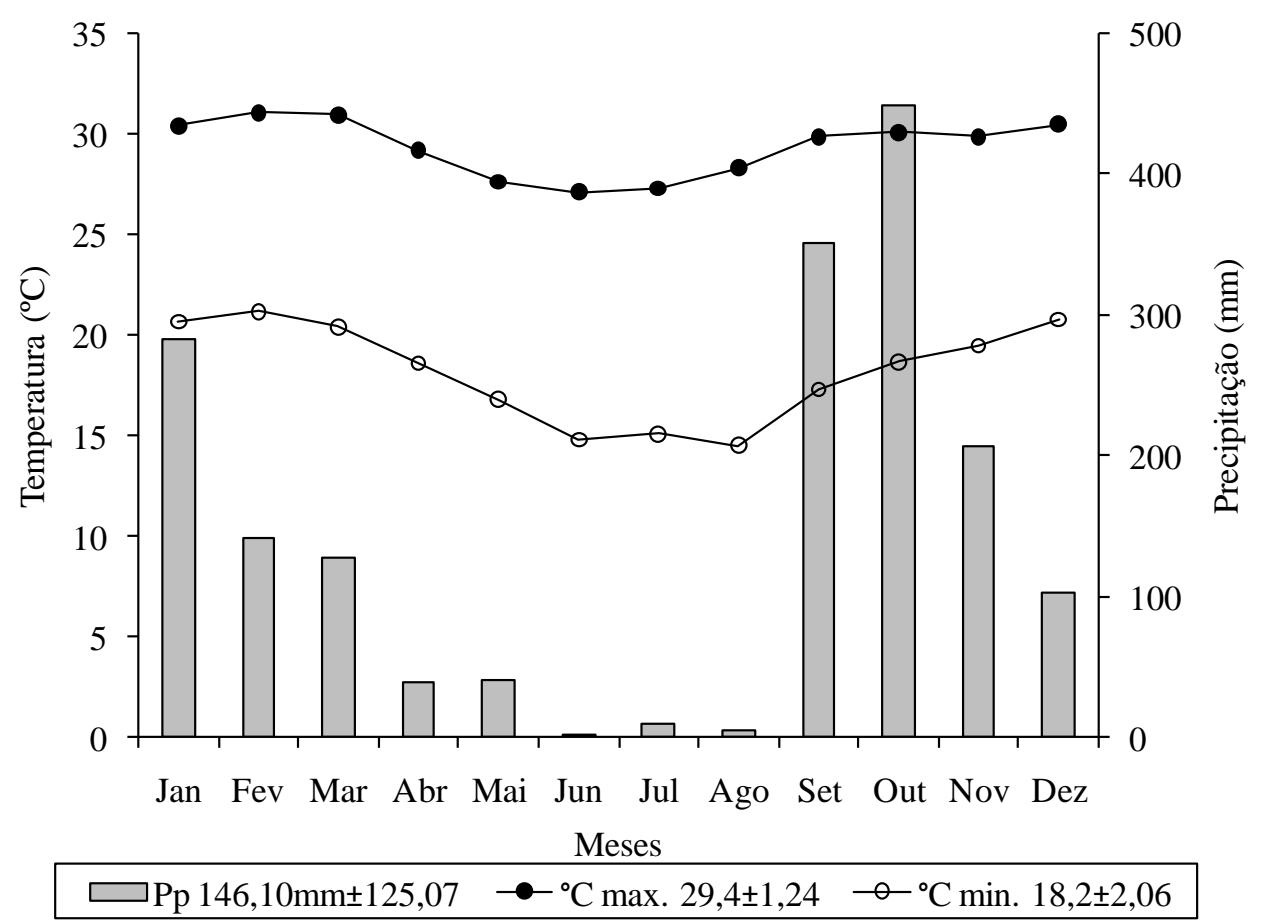

Figura 1. Precipitação pluviométrica $(\mathrm{Pp})$, temperatura média máxima $\left({ }^{\circ} \mathrm{C}\right.$ máx) e mínima $\left({ }^{\circ} \mathrm{C}\right.$ mín), seguidas pelas médias e desvios, no período experimental de 2010, na região experimental no noroeste do Paraná. 
A área experimental foi constituída por capimtanzânia na estação chuvosa de 2009, utilizandose sementes comerciais e seguindo as recomendações do fabricante $( \pm 10 \mathrm{~kg}$ sementes $\left.\mathrm{ha}^{-1}\right)$. Foram aplicadas quatro toneladas de cama de aviário por hectare, aproximadamente $60 \mathrm{~kg}$ $\mathrm{P}_{2} \mathrm{O}_{5}$ ha $^{-1} ; 30 \mathrm{~kg} \mathrm{~N}$ ha $^{-1}$ e $16 \mathrm{~kg} \mathrm{~K}_{2} \mathrm{O}$ ha $^{-1}$, parcelados em duas aplicações, sendo a primeira incorporada ao solo na ocasião de plantio, e a segunda por cobertura no início da primavera.

Foram avaliadas quatro alturas do capimtanzânia sob lotação contínua por bovinos de corte: 20; 40; 60 e $80 \mathrm{~cm}$, distribuídas aleatoriamente em 12 piquetes de 1 ha cada, com três repetições, em uma área levemente ondulada. A altura do dossel era mensurada em 20 pontos aleatórios por piquete, com régua graduada em centímetros. As estimativas de massa de forragem de lâminas foliares verdes, colmos+bainhas e material senescente na pastagem foram realizadas em intervalos de 28 dias, utilizando-se um quadrado metálico, com $0,25 \mathrm{~m}^{2}$, com oito amostras de corte rente ao solo por piquete.

Após a colheita, as amostras foram devidamente identificadas e conduzidas ao laboratório para a separação e pesagem das estruturas morfológicas: lâminas foliares verdes, colmos+bainhas e material senescente. Foram determinadas concentração de matéria seca; proteína bruta; fibra em detergente neutro e fibra em detergente ácido, seguindo metodologia descrita por Mizubuti et al. (2009).

Realizaram-se os ajustes de taxa de lotação, conforme necessidade, em função da altura de pastejo pretendida. Todos os piquetes continham acesso a água à vontade, e houve fornecimento de mistura mineral durante todo o período experimental, visando atender deficiência de macro e micronutrientes.

Para manutenção das alturas, foram utilizados três bovinos por piquete, machos, da raça Nelore, com peso médio inicial de $340 \mathrm{~kg}$, castrados e vermifugados previamente ao experimento. Conforme a necessidade de ajuste para manutenção das alturas, animais adicionais eram introduzidos ou retirados, de acordo com metodologia descrita por Mott e Lucas (1952). Os animais foram pesados no início e no final dos períodos experimentais e a cada 28 dias após jejum alimentar e hídrico de 12 horas, para mensuração da taxa de lotação (UA ha ${ }^{-1}$ ), do ganho de peso corporal médio diário (GMD) e do ganho de peso vivo por hectare $\left(\mathrm{kg} \mathrm{ha}^{-1}\right)$. Devido ao uso de animais adicionais, foi necessário utilizar proporcionalidade quanto à permanência dos animais na área experimental, calculando-se a lotação diária em $\mathrm{kg}$ de peso corporal por hectare e, posteriormente, a lotação média por período em U.A. (unidade animal $=450 \mathrm{~kg}$ de peso vivo ha ${ }^{-1}$ ).

À medida que os animais atingiam peso corporal exigido pelos frigoríficos da região (em torno de $500 \mathrm{~kg}$ de peso corporal), eram abatidos, e seus piquetes de origem mantidos sem taxa de lotação até realização da segunda aplicação da segunda parcela de fertilizantes, já descrita anteriormente.

O período de ocupação e a taxa média de lotação foram determinados pelo tempo necessário para abate de cada piquete, segundo o qual quanto maior o ganho de peso vivo individual, menor o tempo necessário ao abate, e maior o período de descanso até a primavera. Após o abate do lote inicial de animais, os piquetes voltaram a receber nova lotação, simultaneamente ao restabelecimento da altura, após o final do inverno e a observação do efeito da fertilização da primavera.

O delineamento experimental para a avaliação do desempenho foi inteiramente ao acaso, com quatro tratamentos (alturas) e três repetições por tratamento (piquetes). Foram realizados análise de variância $(\mathrm{P}<0,05)$ e procedimentos de regressão para determinar o efeito da altura. Para massa de forragem e composição bromatológica, também foi utilizada análise de variância, e, dependendo da significância dos resultados, procedimentos de regressão em função da altura.

\section{RESULTADOS E DISCUSSÃO}

Para as alturas pretendidas de 20, 40, 60 e $80 \mathrm{~cm}$, encontraram-se alturas de $23,64 \pm 4,38$; $42,92 \pm 3,19 ; \quad 62,73 \pm 2,35$ e $84,36 \pm 4,28$, respectivamente. A massa de forragem de lâminas foliares verdes e colmos+bainhas $\left(\mathrm{kg} \mathrm{ha}^{-}\right.$ ${ }^{1}$ ) apresentou comportamento linear positivo em razão da altura do dossel forrageiro em todas as estações do ano (Tab. 1). Foi observada maior massa de colmos+bainhas em relação a lâminas foliares verdes no verão, outono e inverno, em 
razão, principalmente, da altura de entrada dos animais, quando já havia ocorrido alongamento excessivo dos colmos, problema comumente verificado em pastos de capim-tanzânia. Esse aspecto já havia sido verificado por Barbosa et al. (2006).

Para a realização do ajuste da taxa de lotação com base na massa de forragem, deve-se atentar para o fato de que animais preferem lâminas foliares verdes (Difante et al., 2010), que apresentam maior valor nutritivo em comparação a outras estruturas morfológicas da planta (Cano et al., 2004). Segundo Barbosa et al. (2006), o ajuste da taxa de lotação em função da massa de forragem total pode induzir ao erro, pois pastos com massa de forragem iguais podem conter diferentes massas de matéria seca de lâminas foliares verdes. O que se observa é a elevação da massa de lâminas foliares verdes em função da altura do pasto e, consequentemente, maior possibilidade de seleção da porção ingerida pelos animais.

Tabela 1. Equação de regressão para massa de forragem de lâminas foliares verdes (MLFV), colmos+bainhas (MCOL) e material senescente (MMSE) em pastos de capim-tanzânia sob alturas de pastejo (valores em quilogramas de matéria seca por hectare)

\begin{tabular}{|c|c|c|c|}
\hline Estrutura & Equação & $\mathrm{R}^{2}$ & $\mathrm{P}$ \\
\hline $\begin{array}{l}\text { MLFV } \\
\text { MCOL } \\
\text { MMSE }\end{array}$ & $\begin{array}{c}\text { Verão } \\
\hat{Y}=3039,62+22,0725 \mathrm{x} \\
\hat{Y}=3489,82+44,1922 \mathrm{x} \\
\text { Média geral }=954,44 \pm 964,46(\mathrm{NS})\end{array}$ & $\begin{array}{l}0,62 \\
0,72 \\
\mathrm{NS} \\
\end{array}$ & $\begin{array}{c}0,049 \\
0,048 \\
\text { NS } \\
\end{array}$ \\
\hline $\begin{array}{l}\text { MLFV } \\
\text { MCOL } \\
\text { MMSE }\end{array}$ & $\begin{array}{c}\text { Outono } \\
\hat{Y}=554,995+25,7994 \mathrm{x} \\
\hat{Y}=337,434+91,2212 \mathrm{x} \\
\hat{Y}=7111,84-115,010 \mathrm{x}+1,42263 \mathrm{x}^{2}\end{array}$ & $\begin{array}{l}0,73 \\
0,85 \\
0,93\end{array}$ & $\begin{array}{l}0,000 \\
0,000 \\
0,011\end{array}$ \\
\hline $\begin{array}{l}\text { MLFV } \\
\text { MCOL } \\
\text { MMSE }\end{array}$ & $\begin{array}{c}\text { Inverno } \\
\hat{Y}=694,704+24,0958 \mathrm{x} \\
\hat{Y}=-1176,01+64,9659 \mathrm{x} \\
\hat{Y}=8621,09-255,421 \mathrm{x}+3,99376 \mathrm{x}^{2}\end{array}$ & $\begin{array}{l}0,66 \\
0,73 \\
0,97 \\
\end{array}$ & $\begin{array}{l}0,000 \\
0,000 \\
0,000 \\
\end{array}$ \\
\hline $\begin{array}{l}\text { MLFV } \\
\text { MCOL } \\
\text { MMSE }\end{array}$ & $\begin{array}{c}\text { Primavera } \\
\hat{Y}=1327,09+27,0226 \mathrm{x} \\
Y=524,422+13,3981 \mathrm{x} \\
\hat{Y}=3219,97-79,6278 \mathrm{x}+0,739136 \mathrm{x}^{2}\end{array}$ & $\begin{array}{l}0,67 \\
0,70 \\
0,93\end{array}$ & $\begin{array}{l}0,000 \\
0,001 \\
0,039\end{array}$ \\
\hline
\end{tabular}

$\mathrm{NS}=$ não significativo $(\mathrm{P}>0,05)$.

A altura de pastejo influenciou de modo linear positivo a concentração de fibra em detergente neutro e de fibra em detergente ácido, e de modo linear negativo a concentração de proteína bruta das lâminas foliares verdes, em razão da altura estudada (Fig. 2). O teor médio anual de matéria seca foi de $32,04 \pm 3,56 ; 28,35 \pm 4,72$ e $61,82 \pm 6,62$ nas lâminas foliares verdes, nos colmos+bainhas e no material senescente, respectivamente, sem ocorrência de diferenças estatísticas em razão da altura de pastejo.

Cano et al. (2004) constataram redução da concentração de proteína bruta e da digestibilidade in vitro da matéria seca, com o aumento da altura do dossel do capim-tanzânia, e atribuíram tal efeito ao elevado fluxo de compostos nitrogenados nas folhas mais jovens, decorrente da intensa desfolha em pastos de menor altura de pastejo e do envelhecimento das lâminas foliares naqueles de maior altura.

Houve redução da taxa de lotação de acordo com o aumento da altura do pasto (Fig. 3). O mesmo efeito foi observado por Do Canto et al. (2002), em pastos de capim-tanzânia, na estação seca do ano. Difante et al. (2010) avaliaram a altura de resíduo pós-pastejo do capim-tanzânia e constataram maiores taxas de lotação para menores resíduos pós-pastejo. Ainda, segundo esses autores, podem existir situações em que seja interessante aumentar a taxa de lotação, mesmo que se reduza o ganho de peso individual, mas, em contrapartida, explore-se o ganho por unidade de área de pastagem. 
Desempenho de novilhos...

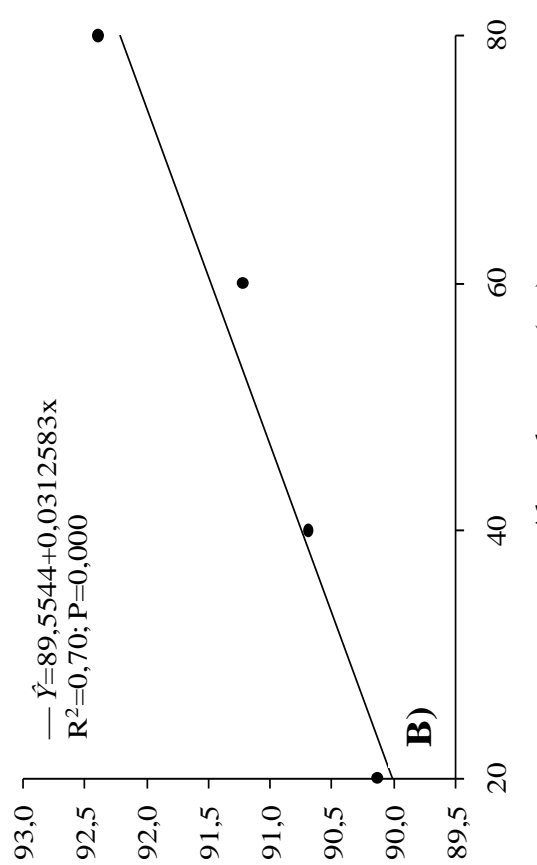

(\%) OW

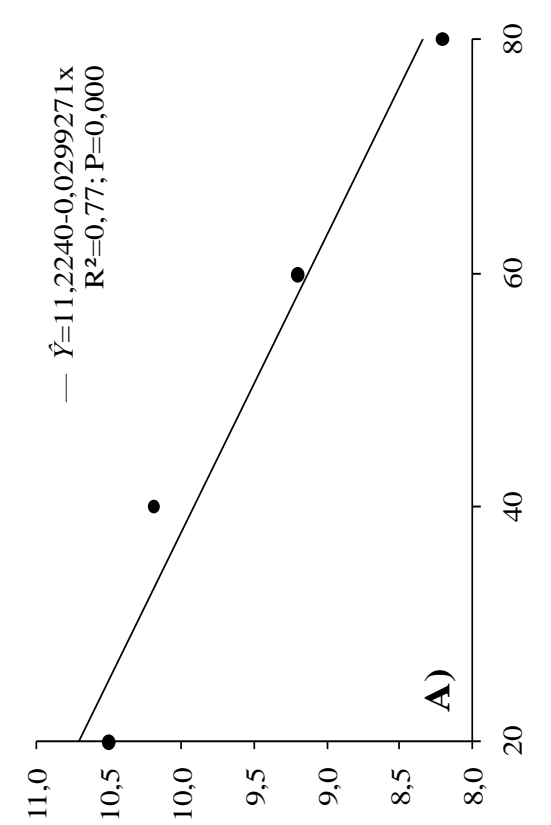

(\%) gd

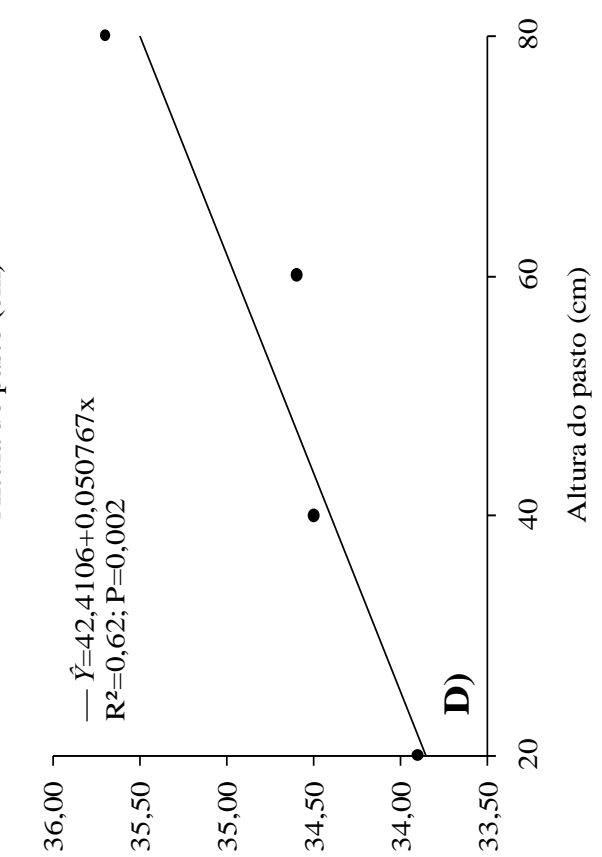

(\%) $\mathrm{VAH}$

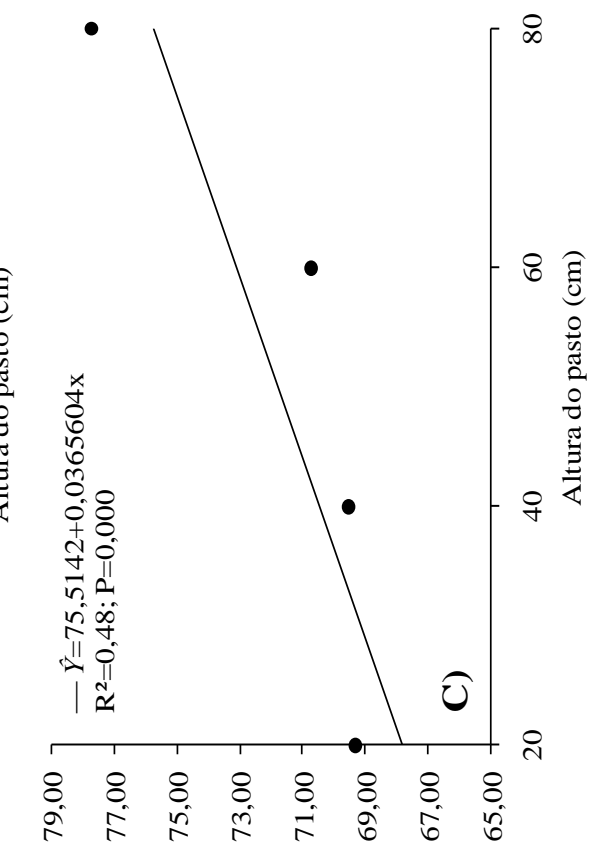

(\%) NGH

Figura 2. Concentração média anual de proteína bruta (A), matéria orgânica (B), FDN (C) e FDA (D) nas lâminas foliares de capim-tanzânia pastejado em 20, 40, 60 e $80 \mathrm{~cm}$ de altura. 

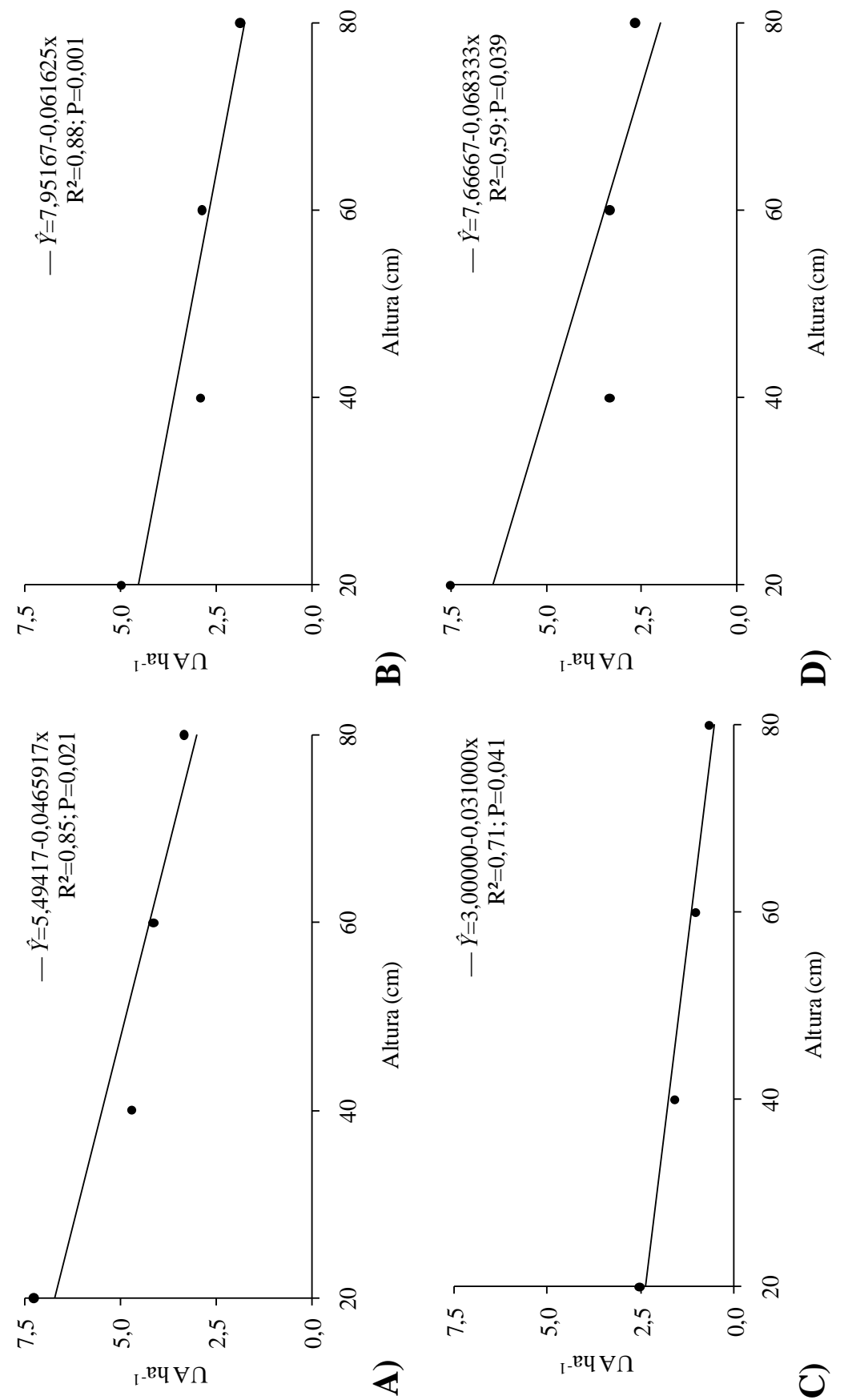

Figura 3. Taxa de lotação de bovinos de corte (UA ha ${ }^{-1}$ ) em pastos de capim-tanzânia, em função da altura de pastejo no verão (A), outono (B), inverno (C) e primavera (D). (Dados obtidos em experimentação, em Cidade Gaúcha, PR, 2010.)

O consumo voluntário de forragem por animal tende a ser maior quando a taxa de lotação empregada, ou pressão de pastejo, é menor, potencializando, dessa forma, o desempenho individual do animal. Contudo, maior lotação pode permitir maior ganho por unidade de área, mesmo que o consumo de forragem por animal e, consequentemente, o desempenho de cada indivíduo sejam menores. 
Foi observado comportamento linear negativo no ganho de peso vivo por hectare $\left(\mathrm{kg} \mathrm{ha}^{-1}\right)$ em razão da altura de pastejo. Comportamento oposto ocorreu no ganho diário por animal $(\mathrm{kg}$ $\left.\mathrm{dia}^{-1}\right)$. O ponto de equilíbrio entre o ganho médio diário e a produção por hectare encontra-se entre as alturas de 40 e $60 \mathrm{~cm}$ de pastejo (Tab. 2). Os animais mantidos em pastos de 80 e $60 \mathrm{~cm}$ atingiram peso de abate em meados do mês de junho de 2010, enquanto os mantidos sob 40 e $20 \mathrm{~cm}$ de desfolha, nos meses de julho e agosto, respectivamente.

Tabela 2. Ganho de peso médio diário (GMD) e ganho de peso vivo por hectare $\left(\mathrm{kg} \mathrm{ha}^{-1}\right)$ de bovinos da raça Nelore, em razão da altura de pastejo do capim-tanzânia nas estações do ano.

\begin{tabular}{|c|c|c|c|c|c|c|c|}
\hline & \multicolumn{4}{|c|}{ Altura $(\mathrm{cm})$} & \multirow{2}{*}{ Equação } & \multirow{2}{*}{$\mathrm{R}^{2}$} & \multirow{2}{*}{$\mathrm{P}$} \\
\hline & 20 & 40 & 60 & 80 & & & \\
\hline \multicolumn{8}{|c|}{ Verão } \\
\hline GMD & $0,954 \pm 0,380$ & $1,070 \pm 0,536$ & $1,078 \pm 0,348$ & $1,273 \pm 0,197$ & $\hat{Y}=0,856944+0,0047444 \mathrm{x}$ & 0,86 & 0,022 \\
\hline $\mathrm{Kg} \mathrm{ha}^{-1}$ & $302,00 \pm 81,37$ & $251,33 \pm 69,12$ & $235,00 \pm 140,71$ & $192,83 \pm 239,62$ & $\hat{Y}=331,250-1,59917 \mathrm{x}$ & 0,85 & 0,025 \\
\hline \multicolumn{8}{|c|}{ Outono } \\
\hline GMD & $0,540 \pm 0,285$ & $0,586 \pm 0,236$ & $0,616 \pm 0,414$ & $0,755 \pm 0,278$ & $\hat{Y}=0,47944+0,00290556 \mathrm{x}$ & 0,66 & 0,040 \\
\hline $\mathrm{Kg} \mathrm{ha}^{-1}$ & $63,00 \pm 32,76$ & $62,66 \pm 56,48$ & $54,16 \pm 44,37$ & $25,15 \pm 38,13$ & $\hat{Y}=50,7500-0,320000 x$ & 0,29 & 0,034 \\
\hline \multicolumn{8}{|c|}{ Inverno } \\
\hline GMD & $0,195 \pm 0,207$ & $0,201 \pm 0,149$ & $0,206 \pm 0,332$ & $0,212 \pm 0,186$ & $\hat{Y}=0,189444+0,00027777 \mathrm{x}$ & 0,10 & 0,045 \\
\hline $\mathrm{Kg} \mathrm{ha}^{-1}$ & $35,66 \pm 31,56$ & $27,77 \pm 14,43$ & $25,42 \pm 46,52$ & $15,66 \pm 9,07$ & $\hat{Y}=32,000-0,113333 x$ & 0,80 & 0,042 \\
\hline \multicolumn{8}{|c|}{ Primavera } \\
\hline GMD & $0,535 \pm 0,200$ & $0,906 \pm 0,273$ & $1,027 \pm 0,218$ & $1,113 \pm 0,246$ & $\hat{Y}=0,476111+0,0079555 \mathrm{x}$ & 0,78 & 0,000 \\
\hline $\mathrm{Kg} \mathrm{ha}^{-1}$ & $290,33 \pm 57,93$ & $282,47 \pm 45,54$ & $255,00 \pm 33,06$ & $233,33 \pm 38,99$ & $\hat{Y}=327,000-1,113333 x$ & 0,75 & 0,025 \\
\hline
\end{tabular}

$\mathrm{P}=$ probabilidade $_{\mathrm{GMD}}=\mathrm{kg}$ animal $^{-1}$ dia- $^{1}$

Segundo Da Silva e Nascimento Júnior (2007), com base em estudos recentes, se os pastos são corretamente manejados, a forragem produzida apresenta pouca variação quanto ao valor nutritivo, mesmo quando se comparam diferentes espécies ou cultivares de plantas forrageiras, e a maior diferença é apenas na quantidade e na distribuição da forragem produzida.

Sistemas pecuários que exploram alta pressão de pastejo podem afetar de forma prejudicial a idade de abate do rebanho, o que resulta em maior tempo para remuneração do capital investido e no abate de animais tardios, com carne de qualidade inferior em relação aos animais abatidos precocemente (Ítavo et al., 2008). Outro fator negativo decorrente da taxa de lotação acima do potencial das pastagens, ou superpastejo, é a degradação das pastagens, que pode exaurir as reservas de nutrientes do solo e gerar alterações prejudiciais à sua estrutura física, o que geralmente resulta em elevados custos de recuperação (Dias Filho, 2011).

A queda significativa de produção por hectare com o aumento da altura do dossel sugere baixa eficiência de transformação de massa de forragem em produto, uma vez que nesses pastos a massa de forragem de lâminas foliares verdes é significativamente maior em razão da altura do pasto. Braga et al. (2007) evidenciaram que a elevada oferta de forragem - 15 a $20 \%$ de OF -, além do impacto negativo na estrutura do dossel forrageiro, gera decréscimo exponencial da eficiência de pastejo, ou seja, a ocorrência de áreas subpastejadas resulta em acúmulo excessivo de massa de forragem de reduzido valor nutritivo.

Em situações em que o mercado pecuário favorece a rápida terminação dos animais, como, por exemplo, em uma perspectiva de alta na cotação dos animais terminados, o objetivo de um determinado sistema pecuário passa a ser o de maximizar o desempenho individual para terminação do animal no menor tempo possível. Nessa situação, todos os esforços são focados em fornecer aos animais uma forragem de qualidade e em quantidade suficiente para potencializar o consumo, e este sistema tende a reduzir a taxa de lotação por área, isto é, indicado para pastos mais altos. Quando o objetivo do sistema pecuário é a maior produção por área, os esforços são direcionados no sentido de aumentar a taxa de lotação, em que a altura de manejo do pastejo é menor.

A avaliação dos efeitos das alturas de pastejo sobre a taxa de lotação, sobre o desempenho e sobre a produção por hectare sugere que o ponto de equilíbrio para manejo de capim-tanzânia esteja entre 40 e $60 \mathrm{~cm}$, o que resulta no bom 
desempenho animal, com boa produtividade por hectare.

\section{CONCLUSÕES}

O ganho de peso médio diário por bovinos de corte apresenta comportamento linear positivo em razão das alturas de pastejo do capimtanzânia, e o contrário é observado para taxa de lotação e ganho de peso vivo por hectare. A altura de pastejo sob lotação contínua entre 40 e $60 \mathrm{~cm}$ apresenta boa associação entre o ganho médio diário e a produção por hectare.

\section{REFERÊNCIAS}

ALMEIDA, R.G.; NASCIMENTO JÚNIOR, D.; EUCLIDES, V.P.B. et al. Produção Animal em Pastos Consorciados sob três Taxas de Lotação, no Cerrado. Rev. Bras. Zootec., v.31, p.852-857, 2002.

BARBOSA, M.A.A.F.; NASCIMENTO JÚNIOR, D.; CECATO, U. Dinâmica da pastagem e desempenho de novilhos em pastagem de capim-tanzânia sob diferentes ofertas de forragem. Rev. Bras. Zootec., v.35, p.1594-1600, 2006.

BARONI, C.E.S.; LANA, R.P.; MANCIO, A.B. et al. Consumo e digestibilidade de nutrientes em novilhos suplementados e terminados em pasto, na seca. Arq. Bras. Med. Vet. Zootec., v.62, p.365-372, 2010.

BRAGA, G.J.; PEDREIRA, C.G.S.; HERLING, V.R. et al. Eficiência de pastejo de capim-marandu submetido a diferentes ofertas de forragem. Pesq. Agropec. Bras., v.42, p.1641-1649, 2007.

CANO, C.C.P.; CECATO, U.; CANTO, M.W. et al. Valor nutritivo do capim-Tanzânia (Panicum maximum Jacq. cv. Tanzânia-1) pastejado em diferentes alturas. Rev. Bras. Zootec., v.33, p.19591969, 2004

CASTRO, G.H.F.; RODRIGUEZ, N.M.; GONÇALVES, L.C. et al. Características produtivas, agronômicas e nutricionais do capim-tanzânia em cinco diferentes idades ao corte. Arq. Bras. Med. Vet. Zootec., v.62, p.654-666, 2010.

CECATO, U.; CASTRO, C.R.C.; DO CANTO, M.W. et al. Perdas de forragem em capim-tanzânia (Panicum maximum Jacq cv. Tanzânia-1) manejado sob diferentes alturas sob pastejo. Rev. Bras. Zootec., v.30, p.295-301, 2001
DA SILVA, S.C.; NASCIMENTO JÚNIOR, D. Avanços na pesquisa com plantas forrageiras tropicais em pastagens: características morfofisiológicas e manejo do pastejo. Rev. Bras. Zootec., v.36, p.122138, 2007.

DIAS FILHO, M.B. Os desafios da produção animal em pastagens na fronteira agrícola brasileira. Rev. Bras. Zootec., v.40, p.243-252, 2011.

DIFANTE, G.S.; EUCLIDES, V.B.P.; NASCIMENTO JÚNIOR, D. et al. Desempenho e conversão alimentar de novilhos de corte em capimtanzânia submetido a duas intensidades de pastejo sob lotação rotativa. Rev. Bras. Zootec., v.39, p.33-41, 2010.

DO CANTO, M.W.; CECATO, U.; ALMEIDA JÚNIOR, R. et al. Produção Animal no Inverno em Capim-Tanzânia Diferido no Outono e Manejado em Diferentes Alturas de Pasto. Rev. Bras. Zootec., v.31, p.1624-1633, 2002.

HODGSON, J. Grazing management: science into practice. New York: Longman Handbooks in Agriculture, 1990. 200p.

ÍTAVO, L.C.V.; DIAS, A.M.; ÍTAVO, C.C.B.F. Desempenho produtivo, características de carcaça e avaliação econômica de bovinos cruzados, castrados e não-castrados, terminados em pastagens de Brachiaria decumbens. Arq. Bras. Med. Vet. Zootec., v.60, p.1157-1165, 2008 .

MIZUBUTI, I.Y.; PINTO, A.P.; PEREIRA, E.S. et al. Métodos laboratoriais de avaliação de alimentos para animais. 1.ed. Londrina: EDUEL - Editora da Universidade Estadual de Londrina. v.1., 2009. 228p.

MOTT, G.O.; LUCAS, H.L. The design conduct and interpretation of grazing trials on cultivated and improved pastures. In: INTERNATIONAL GRASSLAND CONGRESS, 6., 1952, Pensylvania. Anais... Pensylvania State College, 1952. p.13801395.

RIBEIRO, O.L.; CECATO, U.; IWAMOTO, B.S. et al. Desempenho de bovinos em capim-tanzânia adubado com nitrogênio ou consorciado com Estilosantes. Rev. Bras. S. Prod. Anim., v.12, p.275285,2011 